\title{
Bioprospecting, biopiracy and food security in India: The emerging sides of neoliberalism
}

\author{
Sayan Bhattacharya \\ Department of Environmental Studies, Rabindra Bharati University, Kolkata, India \\ E-mail address: sayan_evs@yahoo.co.in
}

\begin{abstract}
Biopirates benefited and prospered from the plundering of natural resources from the developing and less developed countries without paying any royalty to the source countries at all. In the recent past, there have been several cases of biopiracy of traditional knowledge from India. Biopiracy in India was observed in the common plant varieties like Haldi, Basmati, Neem etc. Some cases have been highlighted with a success story, but there are also numerous stories of deprivation in the context of biopiracy. The stealing of biological resources and indigenous knowledge would affect food security, livelihood of indigenous people, and consumers' choice. More than $70 \%$ of our food supply is dependent on a small number of edible plant resources, mainly wheat, maize, rice, and potato, which are fundamental to food security. Patenting of these plants varieties will definitely pose threat to the consumers. In politics, biopiracy has triggered the problem of the intrusion of national sovereignty when a corporation or a government from other countries utilizes and benefits from the patent varieties of genetic resources which derived from genetic resources or traditional knowledge from another sovereign state. However, in the past few years, developing countries have become more vocal in the international arena. This would help developing countries in the political bargaining with developed countries and can help to solve the problem of biopiracy.
\end{abstract}

Keywords: biopiracy; bioprospecting; patent; biodiversity; food security

\section{INTRODUCTION}

In terms of resource use, there are two categories of communities in the world. The ecosystem people are those who depend on the natural environment for satisfying most of their material needs. In contrast, biosphere people command recourses from anywhere in the world, and are not dependent on the local resources for their survival. Here lies the anthropocentric philosophy of sustainability and consumerism. Because of this close interdependence of humans and their environment, the culture of societies is greatly influenced by their environment.

The concept of environment, when explained in terms of biological rights, must also respect the right of other species to survive on this planet. There are millions of species of plants, animals, and microorganisms in the biosphere, and each has a value of its own, a role to play in a vast, complex web of interdependent connections. Human existence and survival is ultimately dependent upon the existence of other organisms. This range of species, the 
habitats they live in, and the internal genetic diversity they display, is called biological diversity or biodiversity. Such diversity is part of our daily lives and livelihoods, constituting resources upon which families, communities, nations and future generations depend. Biodiversity has numerous uses in agriculture, medicine, food and industry. It helps to maintain ecological balance and evolutionary processes, and has spiritual, cultural, aesthetic and recreational values. For thousands of years, biodiversity has been source of useful compounds and materials for food, energy, shelter, medicines, and environmental services.

The economic relevance of biodiversity is increasing because of the changing patterns of consumerism, globalization and emerging environmental problems. It is very difficult to express the overall value of biodiversity in economic terms. However, a recent attempt estimated that biodiversity ecosystem services amounts about US \$ 2.9 trillion for the entire world. Among those estimates, \$ 500 million represents for ecotourism, \$200 million for pollination, \$ 90 million for nitrogen fixation, and $\$ 135$ million for $\mathrm{CO}_{2}$ sequestration worldwide. ${ }^{1}$ A natural ecosystem acts like its own chemical laboratory, with each species experimenting over time with various chemical defenses to ensure survival in the world of natural selection.

They have been synthesizing these compounds for millions of years to protect against predators, infection, pests, and disease. So the plant species are excellent reservoirs of bioactive compounds with the potential for application to treat human diseases. ${ }^{2}$

\section{BIODIVERSITY, BIOPROSPECTING AND BIOPIRACY}

Historically there has been prolific scientific interest in the lifestyles, knowledge, cultures, histories, and worldviews of indigenous peoples. Rural communities depend on traditional knowledge for food, health and agriculture. This traditional knowledge forms the basic cultural identity for them, contributing to social cohesiveness and thereby reducing vulnerability and poverty. $80 \%$ of the world's populations, mostly the 'undeveloped' regions, still rely on the indigenous medicinal knowledge of local plants for their medical needs. ${ }^{3}$ In India, around $70 \%$ of the population directly depends on land-based occupations, forests, wetlands and marine habitats for ecological livelihoods and cultural sustenance. ${ }^{4}$

Over 7500 species of plants and several hundred animal species and also metals and minerals are utilized by the folk tradition in India. The custodians and carriers of these traditions are tribal as well as non-tribals, including house wives and welders, thousand of herbal healers, bone setter, vishvaidyas, birth attendants, potters, gold-smiths, black smiths, barbers and even wandering monks.

According to ASI, there are 4635 ethnic communities in India. In principle each of these communities could be having their own oral medical traditions that have been evolving across time and space. ${ }^{3}$ Traditional knowledge does not only include only the recorded knowledge of plants for medicinal use but also the oral knowledge that has been passed on from generations to generations. In India there have been a lot of cases where the indigenous knowledge has been tried to be taken away. Due to its easy access, it has been prone to piracy. According to UNDP Human Development Report 1999: "The South is the source of 90 per cent of the world's biological wealth - India, for example, has 81,000 species of fauna and 47,000 of flora, including 15,000 plant varieties unique to the country - and yet industrial countries hold 97 per cent of all patents worldwide and are driving the rush to patent plant genetic resources." 5

Today, the genomics revolution is fueling a new wave of scientific research in the form of bioprospecting, and it is impacting the lives of indigenous peoples around the world. 
Bioprospecting involves searching for, collecting, and deriving genetic materials from biodiversity samples that can be used in commercialized pharmaceutical, agricultural, industrial, or chemical processing end products. ${ }^{6}$

The megadiversity countries with $60-70 \%$ of the world's known biological diversity have significant stake for harnessing the potential of biotechnology and bioprospecting for achieving sustainable economic development. ${ }^{1}$ The Convention on Biological Diversity (CBD), the first international treaty provides opportunities to biodiversity rich countries to realize benefits arising out of the utilization of their bioresources. The CBD mentioned that national governments have authority to determine access to their genetic resources, and calls on governments to provide for conservation, sustainable use and equitable sharing of benefits from commercial use of those resources.

Between 4 and 40 million biological species are still unknown in the world. New species are being discovered even today. In the last few decades, biotechnology has developed and played a vital role in the development of the agricultural, pharmaceutical and medical industries. As the importance of the biotechnology industry increases, many useful biotechnological inventions can earn their inventors millions of dollars.

The real pirates are those developed countries, especially the US, who benefited and prospered from the plundering of natural resources from the developing and less developed countries without paying any royalty to the source countries at all. Between 25-50\% of current prescription pharmaceuticals come from plants, either directly or through modifications by biochemical methods, and the value of drugs to the U.S. pharmaceutical industry coming from plant species is estimated at over 30 billion USD per year. ${ }^{2}$ A multinational company or individual who wishes to develop a new product often makes use of the traditional knowledge of local people in deciding upon a plant, animal or other biological source to study.

After the successful production of commercially useful products from those organisms, the company applies for a patent in its own name on those products. In most cases, the inventor not even acknowledges in his patent application that his product was derived from information provided by a local community. Biopiracy therefore can be described as the unjustified extraction of the environmental heritage and traditional knowledge from various regions of the earth for economic exploitation and industrial monopolization. ${ }^{7}$

Daniel F. Robinson distinguished between three different categories of biopiracy:

"Patent-based biopiracy: The patenting of (often spurious) inventions based on biological resources and/or traditional knowledge that are extracted without adequate authorization and benefit-sharing from other (usually developing) countries, indigenous or local communities.

Non-patent biopiracy: Other intellectual property control (through plant-variety protection or deceptive trademarks) based on biological resources and/or traditional knowledge that have been extracted without adequate authorization and benefit-sharing from other (usually developing) countries, indigenous or local communities.

Misappropriation: The unauthorized extraction of biological resources and/or traditional knowledge from other (usually developing) countries, indigenous or local communities, without adequate benefit-sharing." 8

\section{1. Global emergence of Biopiracy}

A recent report of United Nations Development Programme (UNDP) mentioned that "if unpaid royalty payments were being made to developing countries and indigenous peoples for the plant varieties and local knowledge used by multinational food and drug companies, those 
providers would earn approximately 5.4 billion USD per year". ${ }^{2}$ Examples of countries not receiving their full share of these royalties include Tibet, India, Sri Lanka, South Africa, Samoa, Madagascar, Ecuador, Mexico and the Philippines. Since the 1980s, individual inventors or corporations in some countries, such as the United States, Japan, and some European countries, successfully lobbied government to permit exclusive rights to certain biological materials they developed through patenting. They were given exclusive rights to plant and/or reproduce and market them and have the right to prohibit others from planting, reproducing and selling the material provided.

\section{2. Biopiracy in India: few examples}

In the recent past, there have been several cases of biopiracy of traditional knowledge from India. First it was the patent on wound healing properties of haldi (turmeric). ${ }^{9}$ Curcuma longa, a type of turmeric, is an Indian herb that has been used as treatment for sprains, inflammatory conditions and wounds. The orange coloured root is native to the subcontinent and South East Asia, and for thousands of years has been a one of the major components of Ayurvedic medicine. In 1995, two US scientists from the University of Mississippi were granted US patent 5,401,504 on the use of turmeric. The scientists claimed that turmeric could heal wounds and claiming this to be novel. They have mentioned in their patent application that turmeric has long been used in India as a traditional medicine for treatment of various sprains and inflammatory conditions. But they claimed that there was no research on the use of turmeric as a healing agent for external wounds. The Indian government vigorously challenged the patent and provided numerous research papers predating the patent, proving that turmeric has long been used in India to heal wounds. As a result, the US Patent and Trademark office rejected all patent claims related to turmeric. ${ }^{10}$

The Neem tree case is another significant example of biopiracy of Indian medicinal plant. Azadirachtin is one of many active compounds present in bark, leaves, flowers and seeds of the Neem tree or Azadirachta indica. The remarkable properties of this compound have been utilized in India from ancient times in the form of extracts of various kinds produced by Indian farmers and small industrial firms in medicine and agriculture. Use of neem had been described in ancient Indian texts written over 2,000 years ago as an air purifier and effective medicine for almost all types of human and animal diseases because of its insect and pest repellant properties. ${ }^{9,10}$ A US timber importer studied the curing properties of neem and began importing neem seed to his company headquarter in Wisconsin since 1971 . He successfully extracted a pesticidal agent from neem extract called Margosan-O. In 1985, the bio-pesticide derived from neem tree received clearance for the product from the US Environmental Protection Agency (EPA). The patent for the product was sold to the multinational chemical corporation, W.R. Grace after 3 years. Since then, many US and Japanese firms gained patents on formulae for stable neem-based solutions and emulsions and other products. The W.R.Grace approached several Indian manufacturers and industries to purchase their technology. The company ultimately managed to start a joint venture with a firm called P.J. Margo Pvt. Ltd to set up a plant in India. The plant processes up to 20 tonnes of seed a day and also established a network of neem seed suppliers in order to guarantee a constant supply of the seeds at a cheap price. In May 2000, a coalition of groups successfully overturned the patent held by the US company, WR Grace and the US Department of Agriculture over the Indian neem tree. ${ }^{10}$

Basmati is produced largely in Punjab, Western India and in Pakistan. Basmati rice has been one of the fastest growing export items from India in recent times. It is evident that Basmati has been grown for centuries in the subcontinent. After centuries of observation, experimentation and selection, the Indian farmers have developed numerous varieties of the 
rice to meet various ecological conditions, cooking needs and taste. ${ }^{9}$ On 2 September 1997, Texasbased RiceTec Inc. was granted patent number 5663484 for a new plant variety that is a cross between American long-grain rice and Basmati rice. RiceTec claimed that the new varieties have the same or better characteristics as the original Basmati rice and can be successfully grown in specified geographical areas in North America. The patent covers the genetic lines of the basmati and includes genes form the varieties developed by farmers. RiceTec has already been trading rice under brand names such as Kasmati, Texmati and Jasmati. RiceTec's strain possesses the same qualities and characteristics of the Indian traditional varieties of Basmati. On the question of consumer deception, RiceTec clearly labels its product as 'American type Basmati rice'. ${ }^{10}$ No case has been filed in the US so far by any interested party from the Indian subcontinent regarding this serious issue. By mid 2000, however, the Indian government decided to challenge some of the claims of the RiceTec patent. World's largest importer of Basmati rice, Saudi Arabia and the UK, recognized that Basmati rice is unique to Northern India and Pakistan. Furthermore, the Agricultural and Processed Food Export Development Authority and Trade Mark Watch Agency of India have managed to win the Basmati patent case in at least 15 countries (including UK, Australia, France, Spain, Chile and the UAE). In the Basmati case, RiceTec's action would really become a threat to the sales of Basmati rice from India, and could affect the economic conditions of the rice farmers in India.

Karela (bitter gourd), Jamun (blackberry), Gumar and Brinjal, for instance, are commonly known in India for their anti diabetic characteristics. Their usees are so common in India that there is no novelty involved while using them for curbing diabetes. A patent was, however, obtained in the U.S. by three NRIs for their utilization as a cure for diabetes. ${ }^{11}$

North East India is very rich in flora especially in cultivation of medicinal plants by the tribes. Resource-rich Nagaland is plagued by bio-piracy with rare medicinal herbs, orchids and other endangered species being smuggled out of the state. These plants are being borne off by pharmaceutical companies for commercial benefits. Ginseng, taxus baccata and cephallu taxus and paris cordifolia have medicinal properties and are often smuggled to Myanmar. ${ }^{12}$

Some cases have been highlighted with a success story, but there are also numerous stories of deprivation in the context of biopiracy. Corporate patents usually do not recognize or compensate the indigenous people who are the main conservators of those resources. Indigenous communities, over the centuries, have identified and classified plants native to their lands and found their beneficial characteristics. But, the tribes do not have access to legal information that would protect their plants and cultural knowledge nor do they have the finances to obtain them. ${ }^{9}$ The profit incentive companies often overexploit the beneficial plant resources for commercial use, which ultimately result in the loss of forests and genetic material, crisis of land, plants and cultural knowledge of the indigenous communities.

\section{3. Biopiracy and food security}

The stealing of biological resources and indigenous knowledge would affect food security, livelihood of indigenous people, and consumers' choice. More than $70 \%$ of our food supply is dependent on a small number of edible plant resources, mainly wheat, maize, rice, and potato, which are fundamental to food security. Patenting of these plants varieties will definitely pose threat to the consumers. The patenting of biological technology will encourage monopoly control of plant material by Western transnational corporations. Farmers will become dependent of on corporations for their input in agriculture, i.e. seeds, fertilizers, pesticides and herbicides. It has particularly troubling implications for the developing world as the farmers cannot afford to buy seed each year and traditionally set aside a portion of their 
harvest to plant in the next growing season. Moreover, with the introduction of the genetically modified crops and high yielding varieties, the local crop varieties are being lost and outcompeted. ${ }^{13}$ The farmer's rights to choose the desired crops have become difficult to implement. The technology can execute a devastating effect on the economy and food security of the farmers in developing world and can eventually destroy the locally adapted, inexpensive traditional crop varieties. ${ }^{14}$ The entire process will eventually lead to the monopolization of trade, which is ultimately against the principle of free trade fostered by the World Trade Organization (WTO).

India's agriculture being rich in bio-diversity has been always been an easy prey for big corporations engaging in agribusiness for the purpose of bio-piracy. ${ }^{15}$ Monsanto, for instance, tried to spread genetically modified brinjals in India in the form of Bt Brinjals in spite of the fact that India itself is a source of over 2500 different unique varieties of brinjals. ${ }^{16}$ Monsanto's attempt of taking over the market was opposed by the public forcing the government to ban it for an indefinite period of time. ${ }^{16}$ But Monsanto is still stealing native crops, including brinjals, and quietly working on GM varieties of them in test fields, which is a clear violation of India's Biological Diversity Act 2002 (BDA). The farmer variety has been used by Monsanto in its breeding programs without taking prior permission from Indian farmers and without entering into any kind of benefit sharing agreement with them. This is not just grossly unethical; it is in violation of international agreements like the Convention on Biological Diversity (CBD) and the International Treaty on Plant Genetic Resources (ITPGR) which recognize the rights of the farming community over the genetic wealth used in agriculture. ${ }^{17}$

\section{4. Legal perspectives of Biopiracy}

In politics, biopiracy has triggered the problem of the intrusion of national sovereignty when a corporation or a government from other countries utilizes and benefits from the patent varieties of genetic resources which derived from genetic resources or traditional knowledge from another sovereign state. This can violate the international merit of a state's sovereign rights on its own resource.

A study prepared for the UNDP discussed potential strategies to assist indigenous peoples in claiming biodiversity as their own property and to claim financial royalties owed to them by industry. ${ }^{18}$ Some of the proposed steps in this new "intellectual integrity framework" are:

1. Discussion with indigenous communities to learn what steps they wish to take to preserve biodiversity and to properly acknowledge their contributions.

2. New deposit rules should be implemented that would identify biological inventions as to their origin, mentioning the names of individuals or communities concerned, when they are deposited in gene banks or when patent application is made. Failure to provide such 'passport data' could nullify a patent.

3. Tribunals that could resolve disputes between indigenous communities and patent claimants.

4. The creation of a fee structure in each patent jurisdiction that would pay for expenses incurred by indigenous communities for deposits, tribunals and legal representation. ${ }^{2}$ 


\section{CONCLUSIONS}

The predominance of biopiracy in the modern world today in many ways can be considered an outgrowth of the political and economic ideology of neoliberalism (a modern politico-economic theory which favours free trade, privatization, minimal government intervention in business, reduced public expenditure on social services and enhancing the role of the private sector in modern society). ${ }^{19}$ The concept is intimately linked to the concept of intellectual property rights on biological inventions, which is, by itself highly controversial. It is further confusing when the patenting of biotechnology inventions involves a lot of international agreements. There are several concepts that are concerned with biopiracy, including the principle of proprietarian intellectual property rights, community rights, national sovereignty, and the common heritage of mankind, all of them jointly have increased the complexity of the concept. There has not been any law punishing biopiracy because biopiracy is a new kind of crime that specifically emerged only two decades ago. And another reason is that industrialized countries have dominated main international conventions and make the rules accordingly.

Patent law in India needs a wider perspective in order to be protected from being plagiarized by such global giants who are stealing the age-old Indian traditional knowledge. To prevent the hijacking of distinctiveness of our cultural bio-diversity, construction of Traditional Knowledge Digital Library can be an effective way for combating the problem.

However, in the past few years, developing countries have become more vocal in the international arena. They have begun to work cooperatively with each other and form stumbling blocks to industrialized countries. This would help developing countries in the political bargaining with developed countries and can help to solve the problem of biopiracy.

\section{References}

[1] Ministry of Environment and Forests, Govt. of India. 2002. Biotechnology and Bioprospecting for Sustainable Development. India's presentation for the Ministerial Meeting of Megabiodiversity Countries. Cancun, Mexico.

[2] Zakrzewski P. A., Bioprospecting or Biopiracy? The Pharmaceutical Industry's Use of Indigenous Medicinal Plants as a Source of Potential Drug Candidates. University of Toronto Medical Journal 79(3) (2002) 252-254.

[3] Shankar D., Traditional Medicine and Biopiracy. Ancient Science of Life 17(1) (1997) 67-71.

[4] Kothari A., Patel A. 2006. Environment and Human Rights. National Human Rights Commission, New Delhi.

[5] United Nations Development Programme. 1999. Biopiracy and the patenting of staple food crops. Human Development Report, 1999.

[6] Hamilton, C. 2006. Biodiversity, Biopiracy and benefits: What Allegations of Biopiracy tell us about intellectual property. Blackwell Publishing Ltd., Oxford.

[7] Udgaonkar S., The recording of traditional knowledge: Will it prevent 'bio-piracy'? Current Science 82(4) (2002) 413-419.

[8] Robinson D.F. 2010. Confronting biopiracy: challenges, cases and international debates. Earthscan, London/Washington. 
[9] Shiva, V. 1999. Biopiracy: The Plunder of Nature and Knowledge. South end press. India.

[10] Runguphan, T. 2004. Biopiracy in Asia : a case study of India and Thailand. University of Hong Kong, China.

[11] Biopiracy. Accessed from: http://jzsayit.blogspot.in/2010_04_01_archive.html, Accessed on February 21, 2014.

[12] Hindustan Times. May 2, 2008. Biopiracy rampant in Nagaland. Accessed from: http://www.hindustantimes.com/india-news/bio-piracy-rampant-in-nagaland/article1308353.aspx, Accessed on February 21, 2014.

[13] Yusuf M., Ethical issues in the use of the terminator seed technology. African Journal of Agricultural Research 9(52) (2010) 8901-8904.

[14] Bhattacharya S., Chattopadhyay D. J., Mukhopadhyay A., Changing Dimensions of Food Security in a Globalized World: A Review of the Perspectives for Environment, Economy and Health. International research journal of environmental sciences 2(3) (2013) 67-73.

[15] Ministry of Environment and forests. 2010. National consultations on BT brinjals: A primer on concerns, issues and prospects. Centre for environment education, India.

[16] Samuels, J. 2012. Genetically engineered Bt brinjal and the implications for plant biodiversity - revisited. Greenpeace, India. Accessed from:

http://www.greenpeace.org/india/PageFiles/446445/GE-Bt-brinjal-revisited.pdf, Accessed on February 21, 2014.

[17] Intellectual property handbook. Bioprospecting, traditional knowledge and benefit sharing, Concept foundation, Bangkok. Accessed from:

http://www.iphandbook.org/handbook/ch16/, Accessed on February 21, 2014.

[18] TWM. Bio-Piracy Cheats Developing Countries and their Indigenous Peoples of \$5.4 Billion a Year in Plant and Knowledge Royalties, Says Study Conducted for UNDP. Accesses from: http://twm.co.nz/Biopiracy.html., Accessed on February 21, 2014.

[19] Scheper-Hughes, N. 2006. Biopiracy and the Global Quest for Human Organs. NACLA Report on the Americas 39(5): 14-21. Academic Search Premier. EBSCOhost. 